\title{
Trinta anos depois o lema continua vivo: "Democracia é saúde, saúde é democracia!"
}

\author{
Thirty years later, the motto remains alive: "Democracy is health, health \\ is democracy!"
}

\section{Después de trinta años, el lema permanece vivo: "Democracia es salud, salud es democracia!"}

Rodrigo Murtinho | rodrigo.murtinho@icict.fiocruz.br

Fundação Oswaldo Cruz (Fiocruz), Instituto de Comunicação e Informação Científica e Tecnológica em Saúde (ICICT), Laboratório de Comunicação e Saúde (Laces). Rio de Janeiro, RJ, Brasil.

Palavras-chave: Direito à saúde; Movimento da Reforma Sanitária; políticas públicas de saúde.

Keywords: Right to health; health care reform; public health policy.

Palavras clave: Derecho a la salud; reforma de la atención de salud; políticas públicas de salud.

Esta edição da Reciis homenageia dois acontecimentos importantes para a área da saúde, ocorridos há 30 anos, e que estão relacionados à sua trajetória: a $8^{\text {a }}$ Conferência Nacional de Saúde (CNS) e o nascimento do Instituto de Comunicação e Informação Científica e Tecnológica em Saúde (Icict/Fiocruz).

A $8^{\text {a }}$ Conferência Nacional de Saúde representou um marco histórico não só da luta pelo direito à saúde, mas também da participação social nas políticas públicas voltadas para esse campo. A partir dela, as conferências constituíram-se em instrumentos de democratização do Estado, com a participação permanente de "usuários" e de profissionais da área na formulação e no controle das políticas de saúde.

Tendo à frente movimentos e entidades que formavam o movimento da Reforma Sanitária Brasileira (RSB), a "oitava" foi responsável, pós-período ditatorial, pela elaboraração do projeto que levaria ao reconhecimento do direito à saúde na Constituição de 1988 e à construção do Sistema Único de Saúde (SUS). Nesse projeto, baseada em princípios como universalidade, integralidade e equidade, a saúde é concebida como um direito de cidadania e se alicerça numa ideia que extrapola a sua representação como simples ausência de doença. Ela é considerada "resultante das condições de alimentação, habitação, educação, renda, meio ambiente, trabalho, transporte, emprego, lazer, liberdade, acesso e posse da terra e 
acesso a serviços de saúde”. Essa concepção ampliada de saúde foi enfaticamente defendida por Sérgio Arouca, em discurso histórico, na abertura da $8^{\mathrm{a}} \mathrm{CNS} .^{\mathrm{i}}$

Para marcar o trigésimo aniversário da $8^{\text {a }} \mathrm{CNS}$, a Reciis inaugura sua seção de entrevistas com Jairnilson Paim, pesquisador e professor titular do Instituto de Saúde Coletiva da Universidade Federal da Bahia (ISC/Ufba). Nessa entrevista, Paim aborda questões importantes sobre o projeto da Reforma Sanitária Brasileira, a trajetória do Sistema Único de Saúde, a democracia, o momento político atual e sentencia: "Na saúde, tivemos vários momentos muito difíceis, mas conseguimos dar a volta por cima".

Comunicação e informação, como elementos centrais da democracia moderna, estão presentes nas resoluções da $8^{\text {a }}$ CNS e passam a constituir temas permanentes de debates nas conferências de saúde ${ }^{2, i i}$. As preocupações relacionadas a essas áreas se refletiram na criação, também em 1986, da Superintendência de Informação Científica (SIC) na Fundação Oswaldo Cruz. No âmbito da SIC inicialmente foram criados, além do Centro de Computação Científica, o Núcleo de Vídeo da Fiocruz, o setor de programação visual, vinculado à gráfica da Fiocruz, e o Sistema Integrado de Bibliotecas (Sibi).

Com a rápida ampliação das atividades da Fundação nessas áreas, a unidade passou por transformações significativas nos anos seguintes: em 1989 passou a se chamar Superintendência de Informação Científica e Tecnológica (Sict) e, três anos depois, com a ampliação inclusive das atividades de ensino e pesquisa, foi transformada em Centro de Informação Científica e Tecnológica em Saúde (Cict) - unidade técnica de apoio às pesquisas da Fiocruz.

Em 2006, ocorre a mudança mais significativa, com a transformação da nossa estrutura em Instituto de Comunicação e Informação Científica e Tecnológica em Saúde (Icict), unidade técnico-científica da Fiocruz. Esta mudança inclui a qualificação das atividades nas áreas de informação e comunicação, e a ampliação da pesquisa e do ensino na unidade.

Nesse novo cenário, merecem destaque os esforços empreendidos na última década para dar sustentação, fortalecer e desenvolver o campo científico interdisciplinar que reúne informação, comunicação e saúde, sobretudo a construção da Revista Eletrônica de Comunicação, Informação e Inovação em Saúde (Reciis), em 2007; e, no ano seguinte, a constituição do Programa de Pós-Graduação Stricto Sensu em Informação e Comunicação em Saúde (PPGICS).

Esta edição tem, portanto, a missão de celebrar também os 30 anos do Icict, e, em especial, os 10 anos em que a unidade alcançou a condição de Instituto.iii

Com o objetivo de ressaltar os desafios da interdisciplinaridade em nossa trajetória, neste momento de celebração, convidamos Maria Nelida Gonzalez de Gomez, professora do Programa de Pós-Graduação Ciência da Informação da Universidade Federal Fluminense (PPGCI/UFF), para publicar o editorial "Da Interdisciplinaridade às experiências de responsabilidades distribuídas".

Por fim, cabe expressar nossas preocupações diante das mudanças institucionais na condução da política de ciência e tecnologia, com a fusão repentina do Ministério da Ciência, Tecnologia e Inovação (MCTI) e o Ministério das Comunicações (MC). Como mencionado na nota assinada pela Fiocruz, em apoio ao manifesto divulgado pela Sociedade Brasileira para o Progresso da Ciência (SBPC) e Academia Brasileira de Ciências (ABC), há entre os ministérios conflitos claros de missão, visão e objetivos dos dois órgãos.

Diz a nota da Fiocruz: "É notória, cada vez mais e em todo o mundo, a preocupação com o crescimento sustentável dos países por meio do investimento em políticas públicas direcionadas à ciência e à tecnologia,

\footnotetext{
i O vídeo com o discurso de Sérgio Arouca na abertura da 8a CNS está disponível no canal da Videosaúde no youtube: https:// www.youtube.com/watch?v=-_HmqWCTEeQ

ii Para os debates sobre comunicação e informação na 15a CNS, ver: http://pensesus.fiocruz.br/materia carta15CNS e http:// pensesus.fiocruz.br/15a-cns-aprova-moção-pela-afirmação-do-direito-à-comunicação-e-informação

iii Sobre os trinta anos do Icict, ver: http://www.icict.fiocruz.br/content/30-anos e http://www.icict.fiocruz.br/content/linha-dotempo
} 
englobando diversas áreas de atuação dos governos, como saúde, meio ambiente, educação e outras. Ciência e tecnologia são molas propulsoras do desenvolvimento, mas de um desenvolvimento sustentável, voltado para a paz e o bem da sociedade. Ainda há, no Brasil, uma carência de investimentos nos dois setores e a fusão das duas pastas poderá dificultar um crescimento sustentável e de longo prazo”.

Diante do delicado momento político em que o país vive, cabe refletir sobre o lema cunhado pelos sanitaristas no processo de redemocratização do país e a relação intrínseca entre saúde, cidadania e democracia. "Democracia é saúde, saúde é democracia!"

\section{Referências}

1. Brasil. Relatório da 8a Conferência Nacional de Saúde. Ministério da Saúde; 1986.

2. Murtinho R. Estado, comunicação e cidadania: diálogos pertinentes sobre a relação entre direito à saúde e direito à comunicação. [Tese]. Niterói: Universidade Federal Fluminense; 2012. 